\title{
Laboreal
}

Volume $3 \mathrm{~N}^{\circ} 2$ | 2007

Trabalho infantil

\section{As disponibilidades de tempo na construção de normas temporais de trabalho}

Las disponibilidades de tiempo en la construcción de las normas temporales del trabajo

Les disponibilités de temps dans la construction des normes temporelles de travail

Time availabilities in the construction of work temporal norms

\section{Esteban Martinez}

\section{(2) OpenEdition}

Journals

Edição electrónica

URL: http://journals.openedition.org/laboreal/12637

DOI: $10.4000 /$ laboreal. 12637

ISSN: 1646-5237

\section{Editora}

Universidade do Porto

\section{Refêrencia eletrónica}

Esteban Martinez, "As disponibilidades de tempo na construção de normas temporais de trabalho », Laboreal [Online], Volume $3 \mathrm{~N}^{\circ} 2$ | 2007, posto online no dia 01 dezembro 2007, consultado o 24 setembro 2020. URL : http://journals.openedition.org/laboreal/12637; DOI : https://doi.org/10.4000/ laboreal.12637

Este documento foi criado de forma automática no dia 24 setembro 2020. 


\section{As disponibilidades de tempo na construção de normas temporais de trabalho}

Las disponibilidades de tiempo en la construcción de las normas temporales del trabajo

Les disponibilités de temps dans la construction des normes temporelles de travail

Time availabilities in the construction of work temporal norms

\section{Esteban Martinez}

\section{REFERÊNCIA}

Martinez, E. (2007). Les disponibilités de temps dans la construction des normes temporelles de travail. Doctorat en Sciences politiques et sociales, Université Libre de Bruxelles, Bruxelles.

\section{NOTA DO EDITOR}

Manuscrito recebido em : Novembro/2007

Aceite após peritagem em : Dezembro/2007

\section{Introdução}

1 As transformações contemporâneas do tempo de trabalho avaliam-se tomando como ponto de referência a norma temporal fordista que se consolidou, no contexto industrial, como uma combinação complexa entre formas de estabilização da mão- 
deobra, de delimitação do espaço e tempo de trabalho e de uma racionalização tayloriana da produção. Neste contexto, o tempo de trabalho era estritamente medido e delimitado. Desta maneira Pierre Naville (1972) sublinhava a importância chave da dimensão do tempo na análise económica e social já que na sociedade salarial, o tempo divide-se essencialmente em tempo de trabalho e tempo fora do trabalho.

2 No entanto a relação com o tempo mudou durante as últimas décadas, dado que o trabalho se tornou mais complexo, os interesses dos empregadores diversificaram-se num contexto de mutação económica e de procura de maior flexibilidade, e a modificação da composição do assalariado graças ao aumento das qualificações e do emprego feminino. Actualmente contesta-se a categoria do tempo na sua função de medida e de avaliação do trabalho, embora, simultaneamente, esta intervenha mais do que nunca na coordenação do trabalho e da vida social. Deste ponto de vista parece conveniente introduzir na análise o conceito de disponibilidade temporal já que os esforços de sincronização da actividade produtiva e os processos de diferenciação do assalariado, hoje em dia, se baseiam mais em formas de disponibilidade temporal do que em marcos temporais formais.

3 A óptica das disponibilidades de tempo permite, com efeito, ultrapassar, ao englobá-lo, o problema da medida do trabalho através do tempo, dado que a participação dos trabalhadores parece menos regida do que antes pelos limites da duração do trabalho, num contexto em que o resultado prevalece sobre o cálculo das horas ou quando o tempo chega a ser objecto de intercâmbio e em horário irregular. Dito de outra forma, quer se conte ou não o tempo de trabalho, a eficácia da organização apoia-se, de todas as maneiras, na disponibilidade temporal e na implicação subjectiva dos trabalhadores.

4 Esta óptica conduz, igualmente, a deslocar o enfoque da lógica das organizações para a das preocupações dos trabalhadores assalariados, que devem confrontar-se com o desafio que caracteriza a vida quotidiana na articulação com uma pluralidade de tempos. A feminização do emprego constitui aqui um facto social de grande importância, capaz de modificar a relação no que diz respeito ao tempo, tanto na esfera pública como na privada. A participação crescente das mulheres na actividade profissional põe em evidência a pressão que exercem também os tempos da vida privada, que permaneceram muito tempo na sombra do trabalho, quando num universo laboral masculino, o tempo fora do trabalho podia ser considerado como um tempo livre, um tempo de ócio ganho ao trabalho (Adam, 1995).

5 Ao estudar as relações entre os marcos temporais resultantes das formas actuais de organização do trabalho e a experiência temporal dos trabalhadores confrontados com uma pluralidade de tempos sociais, o objectivo é demonstrar, de acordo com Mateo Alaluf (2000), que as formas de disponibilidade temporal e de aceitabilidade das condições laborais são cada vez mais determinantes no funcionamento do mercado de trabalho e na divisão social e sexuada do emprego.

\section{Metodologia}

6 A investigação centrou-se em três grupos profissionais muito distintos no que se refere à qualificação, posição social e género : quadros bancários, enfermeiras hospitalares $\mathrm{e}$ empregados/ as de limpeza. Cada uma das monografias combina dados jurídicos, estatísticos e qualitativos. Numa primeira aproximação, as transformações do tempo de trabalho percebem-se no desenvolvimento de uma regulamentação permissiva. A 
análise dos contractos colectivos põe em relevo o processo de diversificação da organização temporal do trabalho. Não obstante, a diferença entre os tempos de trabalho formais, as formas concretas de disponibilidade temporal são pouco visíveis na codificação jurídica ou estatística. Por este motivo, privilegiamos um enfoque metodológico compreensivo, capaz de pôr em evidência as representações do tempo e as inter-relações entre os tempos dentro e fora do trabalho. Nesta investigação tratouse de relacionar o marco temporal instituído através da negociação colectiva, as representações do tempo mobilizadas pelos actores sociais da regulação e a experiência do tempo vivida pelos trabalhadores. Procurou-se pôr em evidência os marcos temporais de referência partindo da análise dos acordos sociais comentados pelos representantes sindicais e das entidades empregadoras. A análise das representações pessoais do tempo baseou-se em entrevistas aprofundadas com uma amostra não representativa de trabalhadores de empresas distintas e pertencentes a cada um dos grupos profissionais estudados. Nestas entrevistas abordaram-se as representações e usos do tempo, as tensões ou convergências que aparecem entre os tempos laborais e os outros aspectos da vida.

7 Este enfoque permitiu destacar diversas modalidades de flexibilização do trabalho e, segundo a tipologia de Javier Callejo (2004), os impulsos sociais da disponibilidade temporal, articulados sobre a profissão, a carreira ou a preservação do emprego.

\section{Enfermeiras hospitalares}

8 As enfermeiras estão expostas a horários de trabalho variáveis e irregulares relativamente às temporalidades sociais comuns. Pondo de lado a perspectiva vocacional que foi atribuída ao trabalho das enfermeiras, nota-se, claramente, que a tolerância destas relativamente aos horários incómodos, pouco compatíveis com as cargas familiares, apoia-se numa implicação positiva com a profissão e a aceitação das imposições objectivas desta actividade. Neste sentido, a disponibilidade temporal das enfermeiras pode qualificar-se como " profissional ", pois o motor da sua implicação resulta da interiorização das exigências da profissão e da adesão aos valores que a comportam.

o desafio para os administradores dos hospitais é combinar o imperativo financeiro com a necessidade de evitar conflitos com as enfermeiras face a um mercado de trabalho tenso. Neste contexto, as obrigações da vida familiar são reconhecidas e legitimam, até certo ponto, mediante a planificação dos horários, a substituição das enfermeiras em folgas compensatórias ou deixando às enfermeiras a possibilidade de se substituírem entre elas. No entanto, esta organização colectiva não é suficiente para solucionar as dificuldades que as enfermeiras encontram na gestão da sua vida diária. Ao fim e ao cabo, as enfermeiras conseguem limitar os períodos de dificuldade através de compromissos individuais, passando a um regime de trabalho a tempo parcial ou recorrendo ao trabalho temporário.

\section{Quadros bancários}

Os quadros bancários formam um grupo profissional heterogéneo com contornos vagos. As suas funções situam-se entre as de empregado administrativo e as dos 
gerentes. A disponibilidade temporal caracteriza-se principalmente neste caso pela elasticidade no fim da jornada que os leva a acumular horas extra face ao horário normal de trabalho. Não obstante, o facto de disporem de uma certa margem de decisão e o facto das horas extras se manterem dentro de limites aceitáveis atenua as tensões entre a vida laboral e a vida privada.

11 A aceitação de durações de trabalho elevadas reenvia para as representações sociais do estatuto, como "assalariado de confiança ». Ter que responder a obrigações de um resultado e para isso não ter que contabilizar o seu tempo é uma forma de se distinguirem. A disponibilidade valoriza-se na medida em que é a expressão do grupo com o qual se identifica ou ao qual quer pertencer. Neste sentido, a disponibilidade dos quadros pode qualificar-se de " corporativa ». As principais motivações são a posição na organização e a evolução na carreira. Porém, nos usos do tempo, a definição dos contornos da categoria profissional e o género são variáveis determinantes.

Assim, exceptuando os gerentes, os quadros médios e técnicos são considerados apenas como empregados que devem respeitar o regulamento do tempo de trabalho. Mas o seu discurso reflecte muito bem a distância que existe entre a aplicação da regulamentação e os usos do tempo. Até certo ponto, as mulheres podem adoptar uma conduta diferente, trabalhando a tempo parcial, limitando-se aos horários mais regulares, sem renunciarem a uma carreira. No entanto, a disponibilidade que se espera dos quadros médios e técnicos converte-se num factor de exclusão na hora de progredir para funções hierárquicas superiores, onde se impõe o modelo masculino. A exigência de disponibilidade temporal associa-se, então, a outros processos selectivos para limitar o acesso das mulheres a posições superiores.

\section{Empregados/as de limpeza}

13 Neste caso, as relações sociais de subcontratação determinam o conjunto das condições de trabalho. As tarefas de limpeza realizam-se nos espaços dos clientes. Por este motivo, o cliente assume uma parte das responsabilidades empresariais. Determina, particularmente, os tempos de trabalho efectivos. Assim, as tarefas de limpeza organizam-se de acordo com um horário descontínuo, com sequências de trabalho com início de manhã bem cedo e tarde pela noite. Desta forma, os trabalhadores da limpeza padecem duplamente o tempo de trabalho. Vêem-se obrigados ao tempo parcial e, por isso, a um salário parcial. À debilidade do salário acresce a submissão a horários diários incómodos. A estes elementos é preciso acrescentar a violência a nível das relações de trabalho: num contexto marcado pela existência de um conflito permanente sobre o problema da duração e do horário de trabalho instaura-se a disciplina através de ameaças de desemprego. $O$ aviso que anuncia um possível despedimento converte-se no meio de comunicação entre a hierarquia e os trabalhadores.

14 A tolerância dos empregados de limpeza face às más condições de trabalho explica-se pela vontade de "ganhar horas", seja fazendo horas complementares, seja somando vários empregos. Neste sentido, a disponibilidade temporal provém de uma lógica de subsistência económica. Preservar o emprego é o que constitui o motor.

15 A dimensão de género instaura outra linha de divisão entre os trabalhadores do sector. A divisão sexual do tempo de trabalho comporta a divisão de tarefas e as representações dos papéis masculinos e femininos na família e no trabalho. 
Inclusivamente, se inicialmente ambos estão submetidos a obrigações temporais comparáveis, as desigualdades são palpáveis. Os homens ocupam mais amiúde empregos a tempo inteiro enquanto que as mulheres devem resignar-se com as “ migalhas de emprego ", segundo a expressão de Tânia Angeloff (1999).

\section{Conclusões}

16 Quer resultem de acordos formais ou de pactos sociais implícitos, a disponibilidade temporal pode perceber-se como um esforço de coordenação temporal concedido pelos trabalhadores a sistemas de emprego marcados pela flexibilidade da organização do trabalho e a transformação das formas de subordinação salarial. Deste ponto de vista, as exigências de disponibilidade temporal participam na transformação de uma norma social de emprego que foi consolidada no pós-guerra e que implicava uma maior regularidade nos tempos de trabalho e uma forte sincronização dos tempos sociais (Prieto, 1999). Todavia, cabe a interrogação sobre a apreensão do tempo de trabalho como condição de trabalho, isto é, como objecto de negociação colectiva. A qual, actualmente, levanta grandes desafios num contexto que os pactos temporais implícitos se afastam dos marcos formais ou quando a organização do trabalho já não é algo a construir na empresa dado que parece impor-se a partir das exigências do mercado.

17 No que se relaciona com os processos de construção de normas temporais de trabalho, não constatamos a substituição de uma norma temporal “ estandardizada » baseada em empregos estáveis, a tempo inteiro e com horários colectivos, por outra, que seja flexível, que se possa caracterizar de maneira unívoca pela instabilidade do emprego, o trabalho a tempo parcial e horários individualizados. Vê-se que as temporalidades do trabalho inscrevem-se em relações sociais de trabalho diferenciadas e desiguais. Assim, a maneira diferenciada de reconhecer a disponibilidade temporal dos trabalhadores contribui para a segmentação do mercado laboral. Enquanto que esta é tida em conta de forma implícita no caso dos quadros bancários que beneficiam de compensações simbólicas e materiais, ignoram-se largamente no caso da subcontratação, quando a aceitação de horários e jornadas de trabalho atípicas condiciona o acesso ao emprego. Igualmente, no contexto de uma repartição desigual do trabalho doméstico e parental, se a disponibilidade relativamente à família é tida em conta no caso das enfermeiras, dando lugar a revisões da organização do trabalho, é ignorado no caso das gerentes bancárias ou das empregadas de limpeza.

18 As variantes que assume a norma temporal flexível emergente reflectem as divisões sociais e sexuais do emprego. Assim, ter em conta as disponibilidades de tempo permite aprofundar a análise de segmentação do mercado de trabalho, ao distinguir um regime flexível autónomo, atribuído aos gerentes, e um regime flexível heterónomo, caracterizado pelo trabalho a tempo parcial imposto (Bouffartigue \& Bouteiller, 2003) ou por estratégias de redução de custos salariais baseados seja na desconexão parcial do tempo e do salário, seja no cálculo estrito do tempo de trabalho (Rubery, Ward, Grimshaw \& Beynon, 2005). 


\section{BIBLIOGRAFIA}

Adam, B. (1995). Time Watch. The Social Analysis of Time. Cambridge : Polity Press.

Alaluf, M. (2000). Le travail du temps. In G. de Terssac et D.-G. Tremblay (sous la direction de) (204-216), Où va le temps de travail ? Toulouse : Octarès.

Angeloff, T. (1999). Des miettes d'emploi : temps partiel et pauvreté. Travail, Genre et Sociétés, 1, 43-70.

Bouffartigue, P.\& Bouteiller, J. (2003). À propos des normes du temps de travail. De l'érosion de la norme fordienne aux normes émergentes. Revue de l'IRES, 42, 1-23.

Callejo, J. (2004). Disponibilidad temporal corporativa y género : aproximaciones empiricas, Anduli. Revista Andaluza de Ciencias Sociales, 4, 31-60.

Naville, P. (1972). Temps et technique. Les structures de la vie de travail. Genève, Paris : Librairie Droz.

Prieto, C. (1999) (ed.). La crisis del empleo en Europa. Germania : Alzira Rubery, J., Ward, K., Grimshaw, D. \& Beynon, H. (2005). Working Time, Industrial Relations and the Employment Relationship. Time and Society, 15, 1, 89-111.

\section{AUTOR}

\section{ESTEBAN MARTINEZ}

Université Libre de Bruxelles - METICES 44, Avenue Jeanne - B 1050 Bruxelles Belgique emartin@ulb.ac.be 